\title{
Using Electric Vehicles and Demand Side Response to Unlock Distribution Network Flexibility
}

\author{
Hasan Berkem Sonder, Liana Cipcigan, Carlos Ugalde Loo \\ School of Engineering \\ Cardiff University \\ Cardiff, UK \\ HasanBerkemS@cardiff.ac.uk, Cipciganlm@cardiff.ac.uk, Ugalde-looc@cardiff.ac.uk
}

\begin{abstract}
The transportation sector is one of the largest sources of greenhouse gas emissions. This has encouraged governments worldwide to fund the development of ultra-low carbon emission vehicles and replace internal combustion engine (ICE) vehicles with electric vehicles (EVs). Among EV drivers, 'range anxiety' is one of the main issues resulting from long charging durations. The reduction of charging duration by the introduction of DC fast/rapid charging stations is widely discussed in the literature. However, high charging demands due to fast charging stations may cause some challenges for power networks. In this paper, the impacts of different types of fast chargers on a UK generic distribution network are investigated. The most suitable and robust connection points of the network where fast chargers can be deployed are identified without affecting the stability and security of the system. The main findings show that network losses increase, voltages operate beyond strict limits, and system equipment becomes overloaded with increased fast charging activities in the network. Therefore, critical network points are reinforced with distributed generation units (DG) and static VAr compensator (SVC) devices to improve the system reliability and mitigate the impacts of such challenges.
\end{abstract}

Index Terms-DC Fast charging stations, electric vehicles, load flow analysis, network losses, voltage control

\section{INTRODUCTION}

The transportation sector generates one of the largest shares of greenhouse gas (GHG) emissions. GHG emissions result from burning of fossil fuels for trucks, cars, trains, planes, and ships. In 2013, the sector accounted for nearly $64 \%$ of the world's oil consumption [1]. It is also nearly responsible for one-quarter of the global GHG emissions and one-fifth of the current global primary energy use [2], [3]. Increased dependence on burning of fossil fuels has accelerated the funding and development of ultra-low carbon emission vehicles on roads. National governments worldwide want to achieve the electrification of the transport sector by replacing internal combustion engine (ICE) vehicles with electric vehicles (EVs) to increase the adoption of smart energy technologies and reduce the use of fossil fuels [2], [4]. According to the Electric Vehicle Charging Information System, EVs reduce around 2.3 tons of carbon dioxide annually [5]. EVs also have a higher efficiency and a quieter operation than ICE vehicles [6], [7]. Moreover, EVs can take part in demand response (DR) programs by operating as a storage device or controllable load to facilitate the integration of renewable energy systems (RESs) into the grid [8].
On the contrary, the main concerns with the EV technology include the limited capacity of existing power networks, lack of charging infrastructures, limited charging options, long charging durations, limited driving ranges of vehicles, and high investment costs due to high battery prices [6], [9]. Among the $\mathrm{EV}$ drivers, 'range anxiety' is one of the main issues due to long charging durations and lack of charging infrastructures. This anxiety is the ultimate fear of drivers ending up with empty batteries at remote places or long-distance trips [?]. Increasing the capacity of batteries is one way of addressing this issue; however, this increases the vehicle's weight and price. Therefore, reducing the long charging duration by introducing DC fast/rapid chargers, and improving charging infrastructures are considered as the most effective solutions in the literature [11]-[14].

The main questions yet to be solved in the literature are: "What challenges will fast chargers bring for grids, and what can be done to reduce the impact of these challenges?" [11]. There is a limited amount of work quantifying the impacts of fast chargers from a grid's perspective since this type of charging technology is still immature [15]. To bridge this research gap, this paper investigates the challenges introduced by the connection of different types of fast chargers into a system. The UK Generic Distribution Network is adopted to conduct simulation studies. Different solutions are also presented, such as reinforcing the critical parts of the network to facilitate the connection of fast charging stations without affecting the security and stability of the system.

This paper is arranged into sections. Section II briefly presents different types of EV battery charging technologies and summarises the existing literature work by focusing solely on the impacts of fast chargers from the perspective of electrical grids. The network model designed and studied in this work is presented and described in Section III. The research methodology and results of different case studies and scenarios are reported and discussed in Section IV. Conclusions are presented in Section V to close the paper.

\section{Electric Vehicle Battery Charging Strategies}

There are three main EV battery charging levels in the current market. Level 1, termed 'slow-speed', operates at 120 $\mathrm{V}$, whereas Level 2, or 'medium-speed', operates at $240 \mathrm{~V}$. Level 3, or 'high-speed', is used for $480 \mathrm{~V}$ or higher voltage 
levels [13]. Levels 1 and 2 are also referred to as 'normalcharging' and are widely adopted for residential outlets. Most Level 1 charging units are rated up to $2 \mathrm{~kW}$ and Level 2 units are designed to charge EVs with an electric output ranging between 4-20 kW [16]. The time duration to charge a fully depleted EV battery may last between 5 to 15 hours for normal charging [17].

\section{A. Level 3 DC Fast/rapid public charging technology}

Level 3 technology is mainly referred to as fast/rapid DC chargers and present the most advanced charging solutions in the industry, with higher power ratings than normal-charging technologies. Level 3 chargers have four standards available in the market: the Chinese GB/T, Combined Charging System (CCS), Tesla Supercharger (SC) and the Japanese CHAdeMO (CHArge de MOve - move by charge) standard [18]. The Japanese CHAdeMO standard is the most publicly available option with an output of $50 \mathrm{~kW}$. In addition, Tesla SCs output up to $135 \mathrm{~kW}$ [13], [19]. Level 3 chargers are designed to reduce the risk of 'range anxiety' and preserve smooth traffic operation by achieving an $80-90 \%$ state of charge in half an hour [19].

Since EVs are still not capable of charging at speeds similar to traditional gas refueling ICE vehicles, long queues and long waiting times may develop at fast charging stations during peak traffic rush hours [14]. The authors in [12] and [20] therefore proposed ultra-fast charging (UFC) technology to reach the charging speeds of traditional ICE vehicles. For instance, Porsche has undertaken a pilot project by developing a prototype ultra-fast charger rated at a $350 \mathrm{~kW}, 800 \mathrm{~V}$ charging station in Berlin in 2017. Nevertheless, there is no other vehicle capable of receiving a $350 \mathrm{~kW}$ charging power at the time of writing this paper and, therefore, there are many uncertainties and difficulties in determining the gridside challenges of future power networks. However, network infrastructures will need to considerably change to withstand very high charging demands of UFC stations [13].

\section{B. Impacts of fast chargers on electrical grids}

Fast charging an EV means delivering high amounts of energy from the grid into the battery packs within (usually) a range of minutes. For instance, a station charging 10 simultaneous EVs with an electrical output of $100 \mathrm{~kW}$ would exert $1000 \mathrm{~kW}$ of additional energy demand onto the base demand of the grid, and as a result, pulsating loads may be exhibited in the system [10], power losses may increase, critical distribution equipment may be overloaded, and power quality issues may occur in the network [10], [13], [21]-[23].

The limited amount of literature work analysing the impacts of fast charging stations has shown similar findings. Reference [10] showed that fast chargers affect the distribution transformer loading, quality of supply, peak demand (increase by $9 \%$ ) and voltage profiles in the system. Reference [24] demonstrated that increasing the rating of the fast charging equipment worsens the stability of the system. The authors in [25] suggested the installation of fast charging stations in facilities supplied by medium voltage (MV)/low voltage (LV) transformers to reduce voltage fluctuations. The authors in [26] showed that network losses and busbar voltages are significantly affected in a rural distribution system with the addition of fast chargers. Several studies suggested the application of power compensation services to reduce the impacts of fast charger stations on the network [10], [25], [27]. In relation to this, this paper considers different voltage control measures and fast charger connection methods to mitigate the impacts of some of these challenges. In addition, several other studies suggested the implementation of smart charging techniques and vehicle-to-grid (V2G) interfaces to control the EV charging [21], [28], [29]; however, these methods increase the cost and complexity of the systems [21].

\section{Modelling And Planning}

The impacts of fast charging stations are investigated on a UK Generic Distribution System, using the IPSA+ Power software tool. The system is a radial suburban network with 102 busbars in total as shown in Fig. 1. The grid is connected to the $275 \mathrm{kV}$ busbar and voltage levels are stepped-down to $132 \mathrm{kV}, 33 \mathrm{kV}, 11 \mathrm{kV}$ and $6.6 \mathrm{kV}$.

\section{A. Voltage limits, ideal tap positions and network design}

Under the Distribution Network Operator (DNO) license obligation, the $132 \mathrm{kV}$ high voltage (HV) buses must operate within strict voltage limits of $\pm 10 \%$, while the $33 / 11 / 6.6 \mathrm{kV}$ MV buses must operate within $\pm 6 \%$ [22]. Equation (1) and Table I are employed to calculate the ideal tap positions for transformers connected at the HV side (HV/MV - 132/33 kV) to support the majority of the network.

$$
\text { Tap position }=\left[1-\frac{\text { Actual Voltage }(\mathrm{kV})}{\text { Target Voltage }(\mathrm{kV})}\right] \times 100 \%
$$

As shown in Table I, negative tap changers (ideal tap positions) are necessarily applied on transformers because negative taps remove the windings and regulate the voltage on the secondary side of the transformer. This is important to make sure that network voltages operate within strict DNO limits. Tap positions (\%) are calculated and nearest (ideal) tap is chosen at $\pm 0.625(\%)$ increment in IPSA+.

TABLE I

DETERMINATION OF IDEAL TAP POSITIONS

\begin{tabular}{|c|c|c|c|}
\hline $\begin{array}{c}\text { Controlled } \\
\text { Bus } \\
\text { Name }\end{array}$ & $\begin{array}{c}\text { Actual/Target } \\
\text { Bus } \\
\text { Voltage (kV) }\end{array}$ & $\begin{array}{c}\text { Tap position } \\
\mathbf{( \% )}\end{array}$ & $\begin{array}{c}\text { Ideal tap } \\
\text { position at } \pm \mathbf{0 . 6 2 5} \\
\text { increment } \\
(\boldsymbol{\%})\end{array}$ \\
\hline 316 & $32.42 / 33$ & 1.76 & -1.875 \\
\hline 357 & $32.13 / 33$ & 2.64 & -2.5 \\
\hline 313 & $31.94 / 33$ & 3.21 & -3.125 \\
\hline 348 & $32.01 / 33$ & 3 & -3.125 \\
\hline 338 & $32.19 / 33$ & 2.45 & -2.5 \\
\hline 342 & $32.66 / 33$ & 1.04 & -1.25 \\
\hline $338 / 2$ & $32.19 / 33$ & 2.45 & -2.5 \\
\hline
\end{tabular}




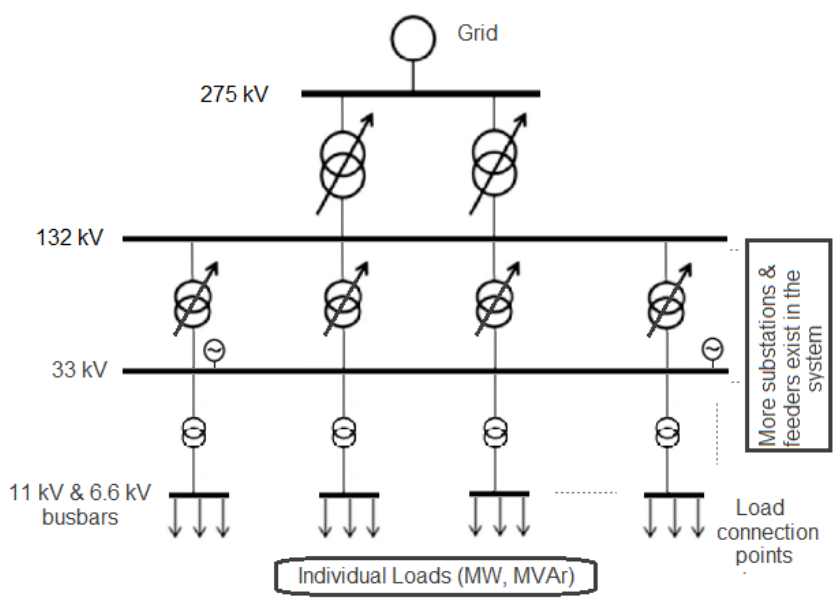

Fig. 1. Simplified one-line diagram of the studied network.

\section{B. Base network demand}

The base network has 25 existing load (demand) points connected at the $11 \mathrm{kV}$ and $6.6 \mathrm{kV}$ MV busbars through twowinding transformers. Each load is modelled as a constant power load and has different demand data (MW) and power factor. The total base network demand is $364.522 \mathrm{MW}$ and this is the demand before any fast charging stations are connected to the network. The base network demand is expected to increase with the connection of fast charging stations and fast charging activities of EVs.

\section{Fast charging station connection points}

This part of the work assumes that each connected fast charging station has five poles in the network, with each pole being able to charge an EV at $50 \mathrm{~kW}$ to represent the CHAdeMO standard rating [18]. In addition, a worstcase scenario is considered to see the impact of simultaneous charging of many EVs on the network by charging each EV at a constant power load of $50 \mathrm{~kW}$ at 0.99 power factor. Fig. 2 illustrates the EV charging process and the connection of fast charging stations to the $11 \mathrm{kV}$ and $6.6 \mathrm{kV}$ feeders.

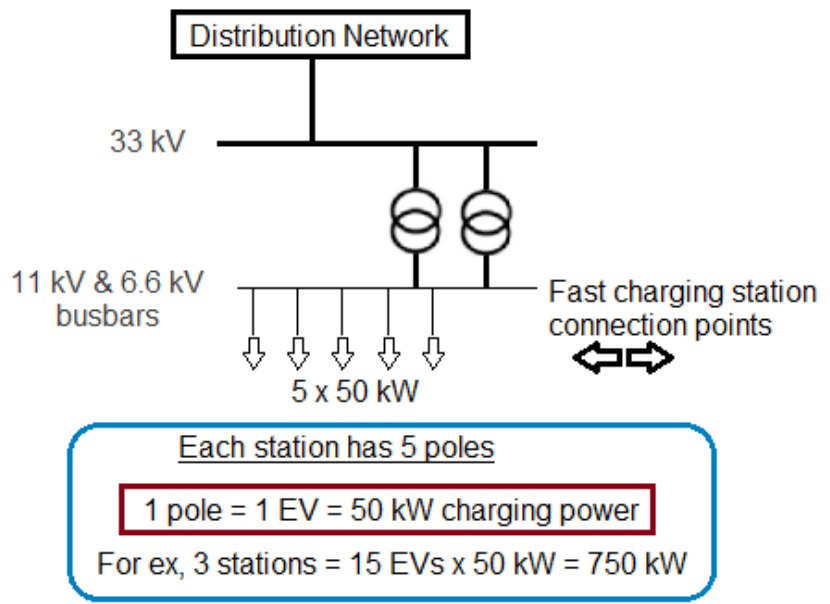

Fig. 2. EV charging process and fast charging station connection points.

\section{RESULTS AND DISCUSSION}

The primary objective of this section is to assess how the UK Generic Distribution Network shown in Fig. 1 is affected following the connection of multiple fast charging stations under different scenarios. Base case is the first scenario and assumes no charging stations, whereas Case 4 is the last scenario with 12 stations connected in the network. In each scenario, 3 additional fast charging stations are connected to different areas of the network, and hence the total demand due to EV charging increases in each scenario. Table II summarises the assumptions and scenarios for the initial part of the analysis.

TABLE II

CONSIDERATIONS AND SCENARIOS FOR FAST CHARGING STATIONS

\begin{tabular}{|c|c|c|c|c|}
\hline Scenarios & $\begin{array}{c}\text { Number } \\
\text { of fast } \\
\text { charging } \\
\text { stations }\end{array}$ & $\begin{array}{c}\text { Number } \\
\text { of EVs }\end{array}$ & $\begin{array}{c}\text { Charging } \\
\text { power } \\
\text { per EV } \mathbf{~ ( k W ) ~}\end{array}$ & $\begin{array}{c}\text { Total } \\
\text { demand } \\
\text { due to } \\
\text { fast charging } \\
\text { (kW) }\end{array}$ \\
\hline Base Case & 0 & 0 & 50 & 0 \\
\hline Case 1 & 3 & 15 & 50 & 750 \\
\hline Case 2 & 6 & 30 & 50 & 180 \\
\hline Case 3 & 9 & 45 & 50 & 2,250 \\
\hline Case 4 & 12 & 60 & 50 & 3,000 \\
\hline
\end{tabular}

\section{A. Impact on network losses and voltage profiles}

The impact of increased fast charging demand on network losses is investigated under different scenarios. Each scenario shown in Fig. 3 represents the amount of losses during three situations: firstly when there are only on-load tap changers (OLTCs) at the HV side to support the majority of the network, secondly when 3 distributed generation (DG) units (total of 5.5 MW capacity) are introduced in critical points of the network, and lastly when static VAr compensator (SVC) devices are used to provide further control measures to the network. According to results, network losses are highest during the first situation; however, the installation of DG and SVC units near chargers contribute to reduction of losses due to additional generation capacity and reactive power compensation.

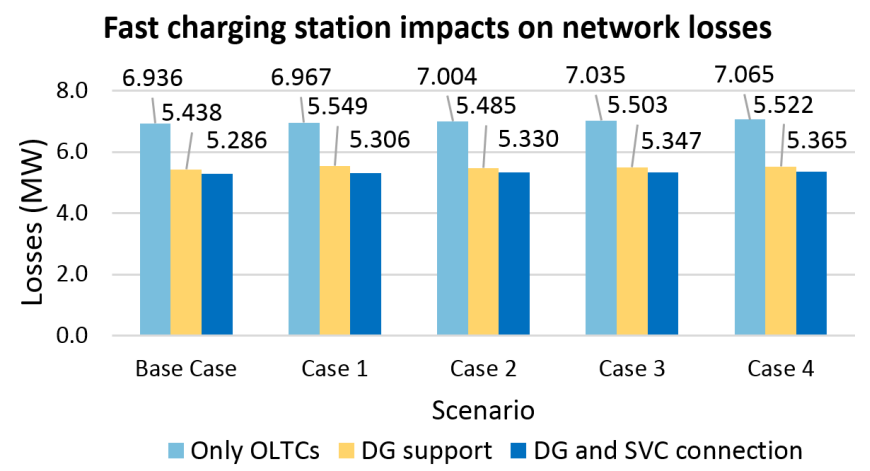

Fig. 3. Network losses under different scenarios and situations. 
The impact of an increased total demand due to fast charging of EVs on network voltages is also assessed. The results compare the voltage drops at the $11 \mathrm{kV}$ and $6.6 \mathrm{kV}$ busbars in each scenario during two situations: firstly when the network operates with OLTCs and has no additional generation capacity (see Fig. 4), and secondly when necessary voltage control measures are provided near certain fast charging stations and critical parts of the network (see Fig. 5).

In the first situation, voltage profiles of the same busbar almost have an equal amount of voltage drop since total demand due to fast charging is considerably small compared to the base network demand. The maximum voltage drop occurs in scenario 'Case 4' since it has the highest number of stations (12) and associated additional demand ( $3 \mathrm{MW})$. On the other hand, four of the connection busbars (1104, 6604, 6607 and 6612) experience voltage violations (see Fig. 4) and operate beyond the DNO target voltage for an MV level (i.e. - 6\%, $<0.94 \mathrm{pu}$ ) since larger demand is consumed near these points.

In the second situation, the critical parts of the network are reinforced due to four busbars not operating within $\pm 6 \%$ limit. The maximum voltage drop is about $2 \%$ lower than the first situation due to the reinforcement. In addition, all connection busbars operate within stable and strict limits due to reactive power compensation services and necessary voltage control measures (see Fig. 5). It should also be emphasised that the distribution network equipment experienced no overloading after the necessary control measures were applied to the critical parts of the network.

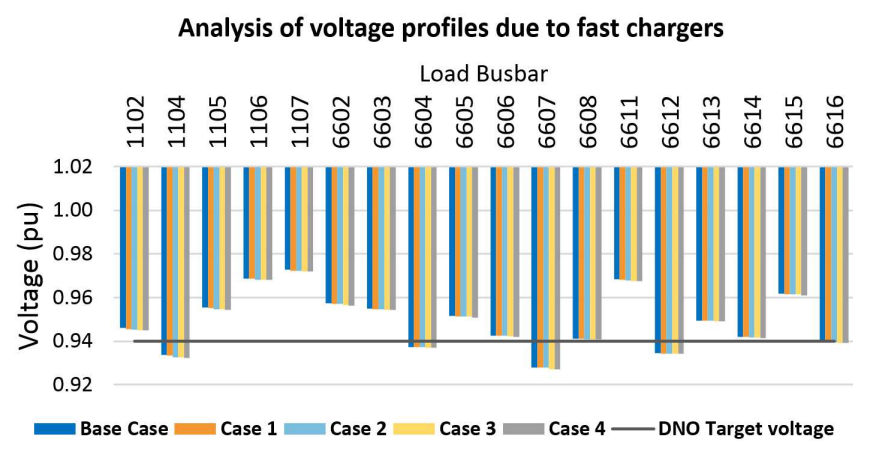

Fig. 4. Voltage profiles in each scenario without additional generation.

Analysis of voltage profiles due to fast chargers (With voltage control) Load Busbar

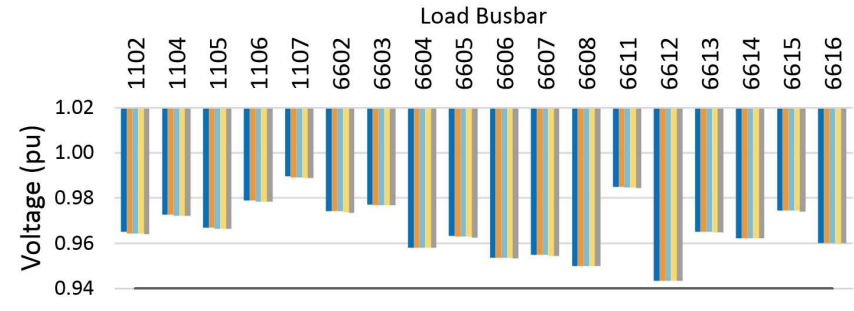

Base Case Case $1-$ Case 2 Case $3=$ Case $4-$ DNO Target voltage

Fig. 5. Voltage profiles in each scenario with necessary voltage control.

\section{B. Evaluation of network for Tesla supercharger connection}

The possibility of introducing $135 \mathrm{~kW}$ Tesla SCs is investigated by considering network flexibility. As of today, there are around 1,441 SC stations with 12,888 Tesla SCs worldwide. In the UK, there are around $45 \mathrm{SC}$ stations actively and most stations consist of $8 \mathrm{SC}$ stalls that can provide a charging power of up to $120 \mathrm{~kW}$ [30]. The primary objective of this subsection is to determine suitable SC connection locations and investigate the limitations of the studied network.

The network adopted for the study (see Fig. 1) is geographically split into 4 different regions (West, East, Southeast and Southwest). Table III summarises all four regions with different possible SC connection points (load busbars). There is a total of 21 possible locations where SCs can be deployed in the network. For instance, the West, Southwest and Southeast regions have 5 possible SC connection points, whereas East has 6.

A load flow analysis is started to determine the robust (i.e. suitable) and critical (i.e. unsuitable) points for SCs. Each region has different connection capacity (suitability level) because each busbar has different characteristic features (i.e. load type and size, demand profile, amount of consumption, cable ampacity, distance to the point of generation).

Therefore, the sutability level of each connection point is affected by the topology of the network.

TABLE III

Network Regions with Possible Supercharger Connection POINTS

\begin{tabular}{|c|c|c|c|}
\hline Regions & $\begin{array}{l}\text { Number of } \\
\text { possible } \\
\text { SC connection } \\
\text { points }\end{array}$ & $\begin{array}{c}\text { Name of SC } \\
\text { connection } \\
\text { points } \\
\text { (Load busbar) }\end{array}$ & $\begin{array}{c}\text { Suitability } \\
\text { level } \\
\text { representation }\end{array}$ \\
\hline \multirow{5}{*}{ West } & \multirow{5}{*}{5} & 6605 & \multirow[t]{2}{*}{ Between 0-4 } \\
\hline & & 6606 & \\
\hline & & 6607 & \multirow[t]{2}{*}{ 0: not suitable } \\
\hline & & 6613 & \\
\hline & & 6615 & 4: most suitable \\
\hline \multirow{6}{*}{ East } & \multirow{6}{*}{6} & 1104 & \multirow{2}{*}{ Between 0-5 } \\
\hline & & 1107 & \\
\hline & & 6602 & \multirow{2}{*}{ 0: not suitable } \\
\hline & & 6610 & \\
\hline & & 6611 & \multirow{2}{*}{ 5: most suitable } \\
\hline & & 6617 & \\
\hline \multirow{5}{*}{ Southwest } & \multirow{5}{*}{5} & 6601 & \multirow{5}{*}{ 0: not suitable } \\
\hline & & 6604 & \\
\hline & & 6609 & \\
\hline & & 6614 & \\
\hline & & 6616 & \\
\hline \multirow{5}{*}{ Southeast } & \multirow{5}{*}{5} & 1105 & \multirow{5}{*}{$\begin{array}{l}\text { Between 0-4 } \\
\text { 0: not suitable }\end{array}$} \\
\hline & & 1106 & \\
\hline & & 1108 & \\
\hline & & 6608 & \\
\hline & & 6612 & \\
\hline
\end{tabular}


The suitability level and flexibility of network regions for SC connections are determined and illustrated in Fig. 6. In order to simplify the presentation of the results, six levels of suitability (0-5) have been proposed (see Table III). The regions with 5 possible $\mathrm{SC}$ connections points (West, Southwest and Southeast) have a suitability level between $0-4$, where level 0 denotes that a particular busbar cannot be used for any SC connection (i.e. unsuitable), whereas level 4 denotes the most suitable connection point. The East region has a suitability level between $0-5$ since it consists of an additional connection point over the other regions. According to results in Fig. 6, busbars 6615 from West, 6617 from East, 6609 from Southwest and 1108 from Southeast are determined to be the most suitable connection points where multiple pairs of SC stalls can be installed.

On the contrary, busbars 6607, 1104, 6604 and 6612 from the West, East, Southwest and Southeast regions, respectively, are not suitable for any SC connection as the network would experience certain under-voltages and overloading violations. This happens due to large loads, high reactive power consumption and line/cable ratings (maximum current capability) in those areas. However, reactive power compensation services can be provided at or near certain connection points to increase the flexibility and suitability level of a particular connection busbar and reduce the impacts of high charging demands in the network.

In addition, over-dimensioning of lines/cables is another solution that may need to be considered by DNOs to increase the capability to withstand higher current flows due to increase in total demand associated with fast charging of many EVs in the network.

The overall results show that the East and Southeast are the most suitable regions for the installation of fast charging stations and Tesla SCs. The suitability level of a particular region and connection point may be affected by the proximity of charging stations or regions to the point of generation, as well as amount of reactive power consumption at particular areas of the network. For instance, the amount of reactive power consumption affects the voltage profiles in the network, and therefore, it becomes crucial to implement voltage control measures when capacitive loads (i. e. leading power factors) are present in the network.

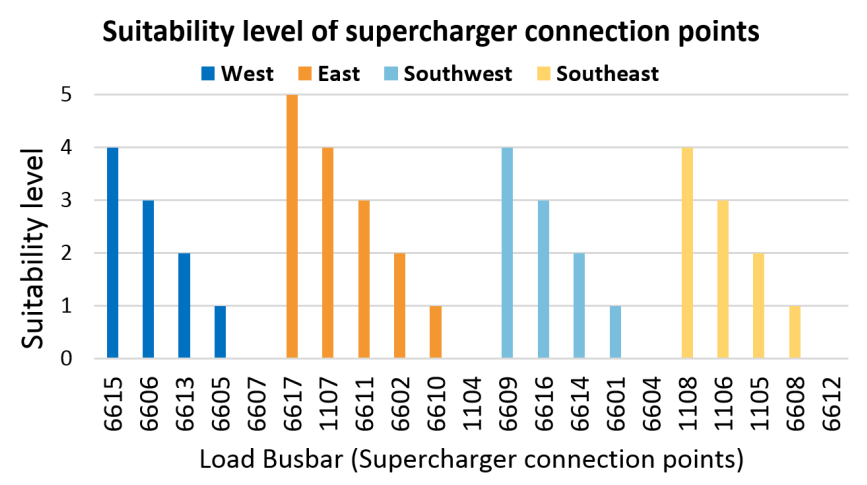

Fig. 6. Suitability level of supercharger connection points in all regions

\section{CONCLUSION}

Level 3 fast/rapid DC chargers are expected to play a big part in the future transportation sector. The technology allows drivers to charge their vehicles on a regular basis and encourages the widespread uptake of EVs. In this paper, the behavior of fast charging of EVs has been modelled and the impacts of the CHAdeMO standard and Tesla SCs have been investigated on a UK Generic Distribution System.

The main findings showed that increased fast charging activities introduce challenges to DNOs, such as increased power losses, higher voltage drops and increased transformer/branch loading in the network. The results also showed that network losses could be reduced up to 22 and $24 \%$ with the connection of DG and SVC units respectively. It was also observed that buses located closer to fast charging stations experience a larger voltage drop than buses located farther away. Furthermore, avoiding the connection of fast chargers near large industrial loads and critical network regions will significantly lower the impacts on electrical grids.

It is always ideal to balance the generation and supply to maintain frequency and keep the system stable. Thus, it is therefore best to carry out a feasibility study and determine the robust points in the network that will be able to tolerate and withstand high charging demands of fast charging stations without affecting the stability and security of the system.

\section{REFERENCES}

[1] K. Kieckhäfer, K. Wachter and T. S. Spengler, "Analyzing manufacturers' impact on green products' market diffusion - the case of electric vehicles," Journal of Cleaner Production, vol. 162, pp. S11-S25, 2017.

[2] W. Tang and Y. J. Zhang, Optimal Charging Control of Electric Vehicles in Smart Grids. Cham: Springer, 2017, pp. 1-6.

[3] E. A. Nanaki and C. J. Koroneos, "Climate change mitigation and deployment of electric vehicles in urban areas," Renewable Energy, vol. 99, pp. 1153-1160, Dec. 2016.

[4] M. Contestabile, M. Alajaji and B. Almubarak, "Will current electric vehicle policy lead to cost-effective electrification of passenger car transport?," Energy Policy, vol. 110, pp. 20-30, Nov. 2017.

[5] M. B. Arias, M. Kim and S. Bae, "Prediction of electric vehicle charging-power demand in realistic urban traffic networks," Applied Energy, vol. 195, pp. 738-753, Jun. 2017

[6] D. Efthymiou, K. Chrysostomou, M. Morfoulaki and G. Aifantopoulou, "Electric vehicles charging infrastructure location: a genetic algorithm approach," European Transport Research Review, vol. 9, no. 2, May. 2017.

[7] S. Zare, P. Najafi, H. Mansuri and H. Taghiya, "New services of plug-in electric vehicles charging stations," in 2016 CIRED Workshop, pp. 1-4.

[8] I. Zenginis, J. S. Vardakas, N. Zorba and C. V. Verikoukis, "Analysis and quality of service evaluation of a fast charging station for electric vehicles," Energy, vol. 112, pp. 669-678, Oct. 2016.

[9] O. Sassi and A. Oulamara, "Electric vehicle scheduling and optimal charging problem: complexity, exact and heuristic approaches," International Journal of Production Research, vol. 55, pp. 519-535, Jan. 2017.

[10] K. Yunus, H. Z. De La Parra and M. Reza, "Distribution grid impact of plug-in electric vehicles charging at fast charging stations using stochastic charging model," in Proc. 2011 14th European Conf. on Power Electronics and Applications, pp. 1-11.

[11] A. Schroeder and T. Traber, "The economics of fast charging infrastructure for electric vehicles," Energy Policy, vol. 43, pp. 136-144, Apr. 2012.

[12] V. M. Iyer, S. Gulur, G. Gohil and S. Bhattacharya, "Extreme fast charging station Architecture for Electric Vehicles with partial power processing," in 2018 IEEE Applied Power Electronics Conf. and Exposition, pp. 659-665. 
[13] D. Meyer and J. Wang, "Integrating ultra-fast charging stations within the power grids of smart cities: A review," IET Smart Grid, vol. 1, pp. $1-8,2018$.

[14] A. Meintz, et. al., "Enabling fast charging - Vehicle considerations," Journal of Power Sources, 367, 216-227, 2017.

[15] C. H. Dharmakeerthi, N. Mithulananthan and T. K. Saha, "Impact of electric vehicle fast charging on power system voltage stability," International Journal of Electrical Power and Energy Systems, vol. 57, pp. 241-249, May. 2014.

[16] B. Sun, T. Dragicevic, F. D. Freijedo, J. C. Vasquez and J. M. Guerrero, "A control algorithm for electric vehicle fast charging stations equipped with flywheel energy storage systems," IEEE Trans. Power Electronics, vol. 31, pp. 6674-6685, Sep. 2016.

[17] P. Phonrattanasak and N. Leeprechanon, "Optimal placement of EV fast charging stations considering the impact on electrical distribution and traffic condition," in 2014 International Conf. and Utility Exhibition on Green Energy for Sustainable Development, pp. 1-6.

[18] B. Morris, L. Michela and Y. Wahiba, "Modelling and simulation of electric vehicle fast charging stations driven by high speed railway systems," Energies, vol. 10, pp. 1268. Sep. 2017.

[19] D. McPhail, 'Evaluation of ground energy storage assisted electric vehicle DC fast charger for demand charge reduction and providing demand response," Renewable Energy, vol. 67, pp. 103-1408, Jul. 2014

[20] M. Vasiladiotis and A. Rufer, "A modular multipower power electronic transformer with integrated split battery energy storage for versatile ultra-fast EV charging stations," IEEE Trans. Industrial Electronics, vol. 62, pp. 3213-3222, May. 2015.

[21] A. Kavousi-Fard, A. Abunasri, A. Zare and R. Hoseinzadeh, 'Impact of plug-in hybrid electric vehicles charging demand on the optimal energy management of renewable micro-grids," Energy, vol. 78, pp. 904-915, Dec. 2014.
[22] J. Y. Yong, V. K. Ramachandaramurthy, K. M. Tan, A. Arulampalam and J. Selvaraj, "Modeling of electric vehicle fast charging station and impact on network voltage," in 2013 IEEE Conf. on Clean Energy and Technology (CEAT), pp. 399-404

[23] G. Mauri and A. Valsecchi, "Fast charging stations for electric vehicle: The impact on the MV distribution grids of the Milan metropolitan area," in 2012 IEEE International Energy Conf. and Exhibition, pp. 1055-1059.

[24] S. M. Alshareef and W. G. Morsi, 'Impact of fast charging stations on the voltage flicker in the electric power distribution systems," in 2017 IEEE Electrical Power and Energy Conference (EPEC), pp. 1-6.

[25] N. Melo, F. Mira, A. de Almeida and J. Delgado, "Integration of PEV in Portuguese distribution grid: Analysis of harmonic current emissions in charging points," in Proc of the 11th International Conf. on Electrical Power Quality and Utilisation, EPQU, pp. 791-796.

[26] E. Akhavan-Rezai, M. F. Shaaban, E. F. El-Saadany and A. Zidan, 'Uncoordinated charging impacts of electric vehicles on electric distribution grids: Normal and fast charging comparison," in 2012 IEEE Power and Energy Society General Meeting Conf., pp. 1-7.

[27] J. Zhao, Z. Xu, J. Wang, C. Wang and J. Li, ’Robust distributed generation investment accommodating electric vehicle charging in a distribution network," IEEE Trans. Power Systems, vol. 33, pp. 4654-4666, Sep. 2018

[28] S. Shokrzadeh, H. Ribberink, I. Rishmawi and E. Entchev "A simplified control algorithm for utilities to utilize plug-in electric vehicles to reduce distribution transformer overloading," Energy, vol. 133, pp. 1121-1131, Aug. 2017.

[29] D. Said, S. Cherkaoui and L. Khoukhi, "Multi-priority queuing for electric vehicles charging at public supply stations with price variation," Wireless Communications and Mobile Computing, vol. 15, pp. 10491065, Apr. 2015.

[30] Tesla.com (2019). Supercharger. Tesla UK. [Online]. Available: at https://tesla.com/supercharger 